Family Profile No. 09, 2018

\title{
Childbearing Desires, Intentions, and Attitudes among Women 40-44
}

Author: Karen Benjamin Guzzo

The delay in parenthood over the past few decades has led to a small but steady increase in childbearing to women over age 40, with childlessness among those 40-44 declining since 2006 (Pew Research Center, 2018). The shifting age profile of first-time childbearing suggests that women at the end of their childbearing years may still be considering having children in the future. This profile documents trends in desired and intended childbearing among women 40-44 as well as attitudes about childlessness, drawing from several cycles of the National Survey of Family Growth (NSFG) representing the years 2002, 2008, and 2013.

\section{Desires to Have a Child in the Future}

The first section examines the proportion of women aged 40-44 who want to have children, having responded affirmatively to the question "Looking to the future, do you, yourself, want to have a(nother) baby at some time in the future?" The figure compares those who already have children to those who do not have children.

- Between 2002 and 2013, the proportion of 40-44-yearold women who wanted to have a child in the future increased among those with and without children.

- More than twice as many childless women reported wanting to have a child in the future than women who already had children.

o In 2002, slightly more than one in three childless women aged 40-44 wanted to have a child compared to one in six mothers.

o In 2013, 42\% of childless women wanted to have a baby in the future compared to only $20 \%$ of their peers who already had children.
Figure 1. Desires to Have Children among Women 40-44, by Childlessness

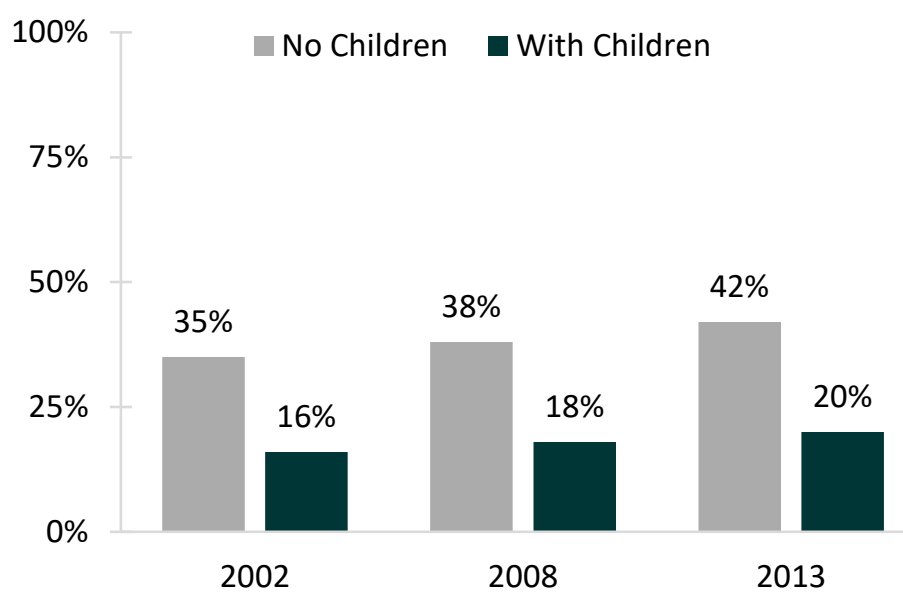

Source: NCFMR analyses of NSFG 2002, 2006-2010, 2011-2015

\section{"More than twice as many childless women reported wanting to have a child in the future than women who already had children."}


Intentions to Have a Child in the Future

$W$ anting to have a child does not necessarily mean a woman actually intends or expects to do so. This section examines the proportion of women who responded affirmatively to the question "Looking to the future, do you intend to have a(another) baby at some time?" Again, mothers aged $40-44$ are compared to childless women 40-44.

- As with desires to have a child, the proportion of women aged 40-44 who intended to have a child in the future was always higher among childless women than among mothers.

- In $2002,16 \%$ of childless women intended to have a baby in the future, rising to around $18-19 \%$ in the later years.

- Among women with children, only $3 \%$ intended to have another child in 2002 and 2008, but the percentage rose to $5 \%$ in 2013.

- Comparing the percentage of women who want a child (Figure 1) with the percentage of women who actually intend to have a child (Figure 2), it is apparent that far fewer women aged 40-44 expect to fulfill their childbearing desires. o In 2016, less than half of childless women aged 40-44 who wanted to have a baby intended to have a baby.

0 The proportion was even lower among mothers aged 40-44, with roughly one-fourth of those who wanted another child intending to have another child.

Figure 2. Intentions to Have Children among Women 40-44, by Childlessness

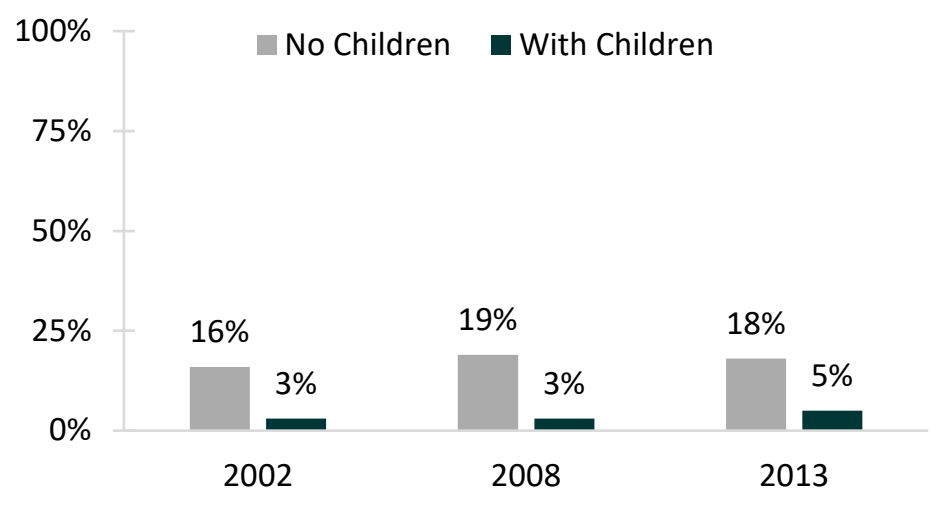

Source: NCFMR analyses of NSFG 2002, 2006-2010, and 2011-2015

Figure 3. How Bothered One Would Be If Never Had Children among Childless Women 40-44

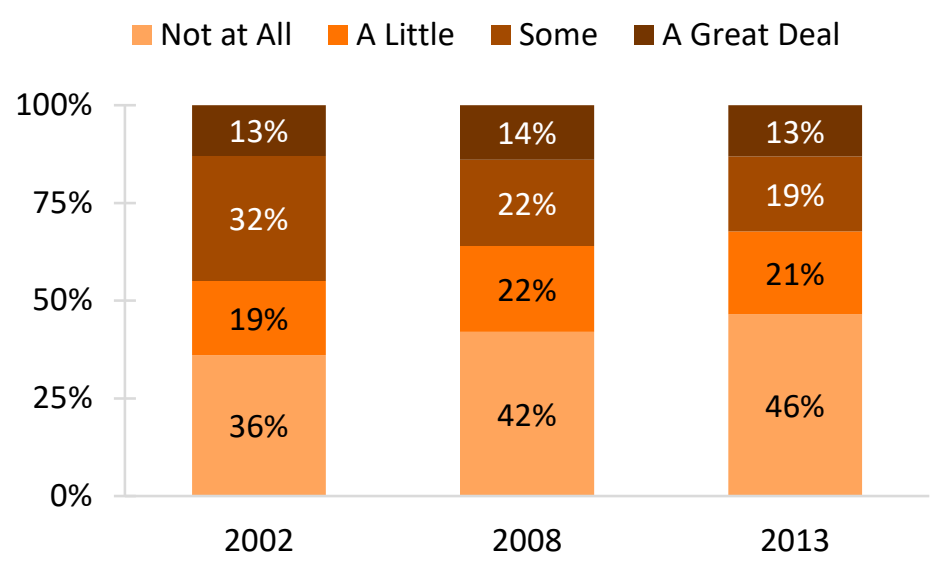

Source: NCFMR analyses of NSFG 2002, 2006-2010, and 2011-2015

Data Source:

National Center for Health Statistics (NCHS), (2016). 2002, 2011-2010, 2011-2013, 2013-2015 National Survey of Family Growth Public Use Data and Documentation. Hyattsville, MD: CDC National Center for Health Statistics. Retrieved from https://www.cdc.gov/nchs/nsfg/index.htm

\section{References:}

Pew Research Center .2018. "They're Waiting Longer, but U.S. Women Today More Likely to Have Children than a Decade Ago." http://assets.pewresearch.org/wpcontent/uploads/sites/3/2018/01/18092036/Pew-Motherhood-report-FINAL.pdf

\section{Suggested Citation:}

Guzzo, K. B. (2018). Childbearing Desires, Intentions, and Attitudes among Women 40-44. Family Profiles, FP-18-09. Bowling Green, OH: National Center for Family \& Marriage Research. https://doi.org/10.25035/ncfmr/fp-18-09.

\section{BCSU. $\mid \begin{aligned} & \text { National Center for } \\ & \text { Family \& Marriage Research }\end{aligned}$}

http://www.bgsu.edu/ncfmr ncfmr@bgsu.edu

(419) 372-3119 